\title{
A Review of Mobile Health Applications in Epidemic and Pandemic Outbreaks: Lessons Learned for COVID-19
}

\author{
Nasim Aslani ${ }^{1}$, Mina Lazem ${ }^{1}$, Somaye Mahdavi ${ }^{2}$ and Ali Garavand (iD) ${ }^{3,}{ }^{*}$ \\ ${ }^{1}$ Department of Health Information Management, School of Health Management and Information Sciences, Iran University of Medical Sciences, Tehran, Iran \\ ${ }^{2}$ Valiasr Specialized Polyclinic of Urmia, Social Security Organization of West Azerbaijan Province, Urmia, Iran \\ ${ }^{3}$ Department of Health Information Technology and Management, School of Allied Medical Sciences, Shahid Beheshti University of Medical Sciences, Tehran, Iran \\ "Corresponding author: Department of Health Information Technology and Management, School of Allied Medical Sciences, Shahid Beheshti University of Medical Sciences, \\ Tehran, Iran. Email: virya67@yahoo.com
}

Received 2020 April 12; Accepted 2020 April 22.

\begin{abstract}
Context: Using smart mobile devices, called mobile health (mHealth), facilitates providing health services, speeds up the process, and reduces the costs and complications of direct services. Also, mHealth has many capabilities and applications in epidemic and pandemic outbreaks. This study aimed to identify mHealth applications in epidemic/pandemic outbreaks and provide some suggestions for tackling COVID-19.

Methods: To find the relevant studies, searches were done in PubMed and Scopus by related keywords during 2014 - 2020 (March 10). After selecting the studies based on the inclusion and exclusion criteria, data were collected by a data-gathering form.

Results: Of the 727 retrieved studies, 17 studies were included. All studies emphasized the positive effect of mHealth for use in epidemic/pandemic outbreaks. The main applications of mHealth for epidemic/pandemic outbreaks included public health aspects, data management, educational programs, diagnosis, and treatment.

Conclusions: mHealth is an appropriate method for encountering epidemic/pandemic outbreaks due to its extensive applications. In the pandemic outbreak of COVID-19, mHealth is one of the best choices to use in the patient-physician relationship as tele-visits, using in fever coach, providing real-time information for healthcare providers, population monitoring, and detecting the disease based on obtained data from different locations.
\end{abstract}

Keywords: mHealth, Pandemic, COVID-19, Outbreak

\section{Context}

Using smart mobile devices, called mobile health (mHealth), facilitates providing health services, speeds up the process, and reduces the costs and complications of direct services $(1,2)$. mHealth is a practice that provides health care services indirectly in wireless and remote communication $(2,3)$. mHealth is a type of health information technology that can be used to provide health care services as a supportive tool. Many apps and software have been developed in a mobile platform in all aspects of health care (3). mHealth can be used in epidemic and pandemic outbreaks because of its accessibility, ease of use, and attracting many users (4). Therefore, in recent years, there has been a growing use of mHealth in epidemic conditions.

Coronavirus 2019 (COVID-19), as a pandemic outbreak, emerged on December 31, 2019, in China and quickly spread around the world $(5,6)$. By March 1, 2020, there were 859,392 affected cases and 42,327 deaths worldwide (7). COVID-19 is a coronavirus disease that appears as a se- vere acute respiratory syndrome with symptoms such as fever, cough, shortness of breath, and sore throat $(5,8,9)$. Given the enormous damage to society, many countries adopted specific policies to deal with COVID-19.

One of the key programs for tackling COVID-19 is the use of information technology, including mHealth. In recent years, mHealth capacities have been used in many countries as a new technology to control epidemic/pandemic outbreaks, with valuable results. Navin et al. (10), in their study in 2017 provided a mHealth solution to use in the public health epidemic surveillance system and it showed a high capability to detect any disease outbreak. Also, Lwin et al. used FluMob, a mHealth app, for tracking influenza by obtaining real-time epidemiological and surveillance data from healthcare providers by allowing them to report influenza incidence using smartphones (11).

Given the importance of mHealth technology in dealing with COVID-19 as a pandemic outbreak, this study 
briefly reviewed studies of the use of mHealth in recent epidemic/pandemic outbreaks worldwide to learn some lessons on how to deal with COVID-19.

\section{Evidence Acquisition}

This review study was done in 2020. To find related studies, searches were done in PubMed and Scopus, as well as Google Scholar, by related keywords (Table 1).

\begin{tabular}{|c|c|}
\hline Search Strategy & Details \\
\hline \multicolumn{2}{|l|}{ Limitations } \\
\hline Time & $2014-2020$ (March, 10) \\
\hline Language & English language \\
\hline \multicolumn{2}{|l|}{ Other limitations } \\
\hline PubMed & Human \\
\hline Scopus & Medicine and article \\
\hline \multicolumn{2}{|l|}{ Used keywords } \\
\hline$\# 1$ & $\begin{array}{l}\text { "pandemic" OR "epidemic" OR "outbreak" OR "corona" } \\
\text { OR “COVID-19" }\end{array}$ \\
\hline$\# 2$ & $\begin{array}{l}\text { “mobile" OR “mobile health" OR “mobile phone" OR } \\
\text { "mHealth” }\end{array}$ \\
\hline \multicolumn{2}{|l|}{ Search } \\
\hline$\# 1$ AND \#2 & \\
\hline
\end{tabular}

We included studies of using mHealth in an epidemic/pandemic infectious disease outbreak and reporting/describing the mHealth application in epidemic/pandemic outbreaks. Studies on other health information technologies such as geographic information systems and telemedicine were excluded from the study. Also, studies not focusing on epidemic/pandemic outbreaks were excluded. Studies that used PC or web-based applications for population tracking and data analysis were removed, as well.

After selecting the related studies, data were extracted using a data extraction form and analyzed by the content validity technique. In this regard, the data were categorized into themes and sub-themes based on the study objectives.

\section{Results}

Of 727 retrieved studies in the initial search, after applying inclusion and exclusion criteria, 17 studies were selected for the study. Table 2 shows the selected studies.

Of 17 reviewed studies, 14 (82.35\%) studies were about epidemic outbreaks, and the rest concerned pandemic outbreaks. All studies emphasized the positive effect of
mHealth in epidemic/pandemic outbreaks. Table 3 shows the location of the studies by countries and the World Health Organization (WHO) regions.

Figure 1 shows the epidemic/pandemic diseases. Based on Figure 1, most of the studies were about Ebola (35.28\%).

The results showed that mHealth can be applied in five main categories (Table 4).

However, the main reason for using mHealth in outbreaks was to support people and patients. Furthermore, health care providers, managers, and policymakers were other mHealth stakeholders.

\section{Discussion}

One of the effective ways of tackling epidemic/pandemic outbreaks is to use communicational health information technologies, such as mHealth. For tackling and controlling COVID-19 as an emerging pandemic, we should use the capabilities and applications of mHealth. Some countries with high epidemic/pandemic outbreaks used mHealth to encounter this condition. The AFRO and WPRO countries had the most use of mHealth in epidemic/pandemic outbreaks. One of the main causes of high-level mHealth use in these two regions can be the high prevalence of epidemic/pandemic diseases.

The results of the study showed that the most use of mHealth was related to Ebola, an infectious disease that is more prevalent in AFRO. Also, for influenza, which has the most similarity to COVID-19 among the mentioned diseases, the policymakers and managers used mHealth, especially in providing remote healthcare services for patients $(17,25)$. The results of the study showed that the application of mHealth in epidemic/pandemic outbreaks can be divided into five main categories, as follows:

\subsection{Public Health Aspects}

One of the most important parts of the control and elimination programs of an epidemic/pandemic outbreak is public health programs (35). Thus, mHealth can be used as a supportive method for implementing public health programs in an epidemic/pandemic outbreak (10). Based on the results of the study, the main role of mHealth is in public health aspects. The most useful application of mHealth was in surveillance purposes, which include community surveillance, healthcare workers surveillance, and real-time surveillance $(10-12,22,25)$. Due to the high prevalence of COVID-19 in the world, its surveillance is very important and mHealth can play a pivotal role. Also, one of the other problems in controlling COVID-19 is inefficient contact tracing (36) to prevent its spread. Research shows that contact tracing and monitoring by mHealth 


\begin{tabular}{|c|c|c|c|c|}
\hline Authors & Year & Study Type & Study Population & Study Objective \\
\hline Navin et al. (10) & 2017 & Developmental & - & $\begin{array}{l}\text { Providing mHealth for detecting any disease } \\
\text { outbreaks }\end{array}$ \\
\hline Toda et al. (12) & 2016 & RCT & 135 participants & $\begin{array}{l}\text { Assessing the text message system for outbreak } \\
\text { alert in Kenya }\end{array}$ \\
\hline o'Donovan and Bersin (13) & 2014 & Correspondence & 167000 users & $\begin{array}{l}\text { Reporting an experience of IBM company about } \\
\text { implementing a mHealth program in three } \\
\text { countries (launching a disease-mapping system) }\end{array}$ \\
\hline Abiola et al. (14) & 2015 & Case report & 100 smartphones & $\begin{array}{l}\text { Contact tracing using ubiquitous sensors present } \\
\text { in the node smartphone application on Android } \\
\text { phones }\end{array}$ \\
\hline Otu et al. (15) & 2016 & Cross-sectional & 203 participants & $\begin{array}{l}\text { Reporting an education intervention that used } \\
\text { tablet computers for health workers training }\end{array}$ \\
\hline Gu et al. (16) & 2015 & Cross-sectional & 9105 users & $\begin{array}{l}\text { Using a mobile internet device to assess KAP } \\
\text { regarding H7N9 among mobile users }\end{array}$ \\
\hline Gashu et al. (18) & 2020 & Review & Articles & $\begin{array}{l}\text { Assessing the effect of mobile phone messaging } \\
\text { on anti-TB success treatment }\end{array}$ \\
\hline Racine and Kobinger (19) & 2019 & Commentary & - & $\begin{array}{l}\text { Reporting challenges and perspectives on the use } \\
\text { of mobile laboratories during outbreaks and } \\
\text { their use for vaccine evaluation }\end{array}$ \\
\hline Danquah et al. (20) & 2019 & Developmental & $\begin{array}{l}26 \text { contact tracing coordinators (CTCs) and } 86 \\
\text { contact tracers (CTs) working in } 11 \text { chiefdoms }\end{array}$ & $\begin{array}{l}\text { Designing and evaluating an electronic system } \\
\text { for tracking contacts of Ebola cases }\end{array}$ \\
\hline Rebaudet et al. (21) & 2019 & - & 7,856 weekly cholera alerts & $\begin{array}{l}\text { Describing and evaluating the exhaustiveness, } \\
\text { intensity, and quality of CATIs in response to } \\
\text { cholera alerts }\end{array}$ \\
\hline Kim et al. (22) & 2019 & Cross-sectional & 7702 influenza reports & $\begin{array}{l}\text { Evaluating the Fever Coach app in real-time } \\
\text { surveillance of influenza activities for children } \\
\text { and parents }\end{array}$ \\
\hline Fujibayashi et al. (23) & 2018 & Cross-sectional & - & $\begin{array}{l}\text { Evaluating the new influenza-tracking mobile } \\
\text { phone app that used a self-administered } \\
\text { questionnaire }\end{array}$ \\
\hline Guetiya Wadoum et al. (24) & 2017 & Cross-sectional & 910 medical consultations & $\begin{array}{l}\text { Identifying the applications of mHealth clinic } \\
\text { developed for Ebola in Sierra Leone }\end{array}$ \\
\hline Rosewell et al. (25) & 2017 & Case study & 160,750 malaria tests & $\begin{array}{l}\text { Describing an m-health initiative to strengthen } \\
\text { malaria surveillance in a 184-health facility, and } \\
\text { provinces }\end{array}$ \\
\hline Lwin et al. (11) & 2017 & Descriptive & Health care workers & Describing the development of FluMob \\
\hline Kuehne et al. (26) & 2016 & Cross-sectional & 6,813 household members in 905 households & $\begin{array}{l}\text { Describing the health-seeking behavior during } \\
\text { the Ebola }\end{array}$ \\
\hline
\end{tabular}

are an appropriate way $(14,20)$. Thus, it is proposed to use mHealth capabilities for contact tracing of COVID-19 cases. Also, mHealth can be used for vaccine reminder systems, epidemic tracking, public awareness, trend analysis and forecasting, health-seeking behavior, and patient selfmonitoring $(23,26,28-30)$. All of these applications can be used for COVID-19 as an emerging pandemic outbreak.

\subsection{Data Management}

In an outbreak condition, data management is an important function that is a foundation for other practices and programs (37). mHealth technology can be used as a key method for better data management in outbreaks (38). Moreover, mHealth can be used for data collection (22), data transmission between healthcare centers (31), health disparities reduction due to facilitating data ex- change (17), easy access to near real-time information (23), and timely, high quality, geo-coded, and case-based data provision (25). In the case of COVID-19, the use of mHealth is recommended due to the importance of timely and accurate data exchange (39).

\subsection{Educational Programs}

Patient and public education, as well as healthcare provider training, is very important during an epidemic/pandemic outbreak (40-42). Research shows that mHealth is an effective method for implementing educational programs during an epidemic/pandemic outbreak $(15,32)$. Moreover, mHealth can be used to identify sociodemographic information for people education (16) by the analysis of available data. This is an appropriate method to educate people about COVID-19 based on their 


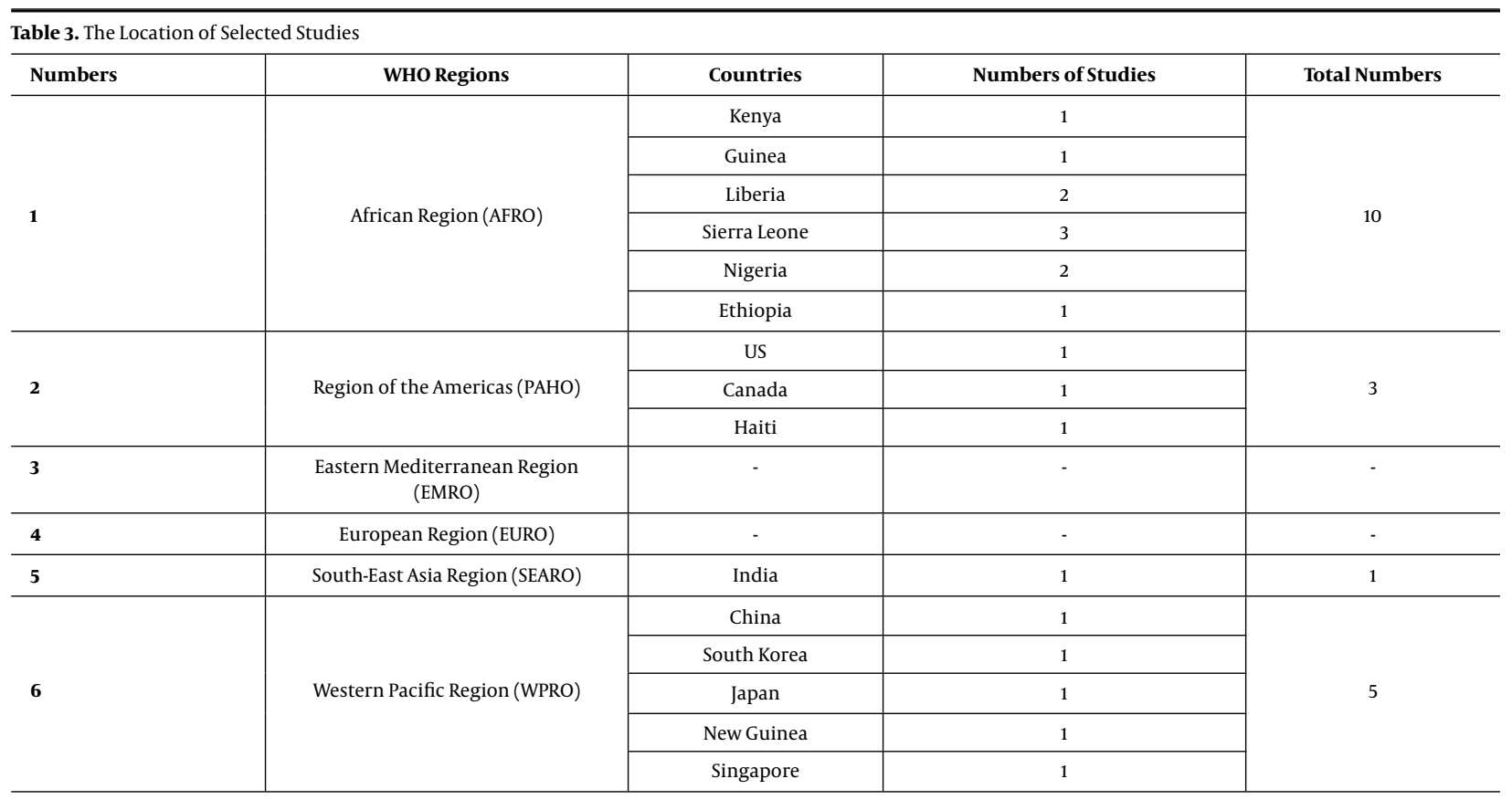

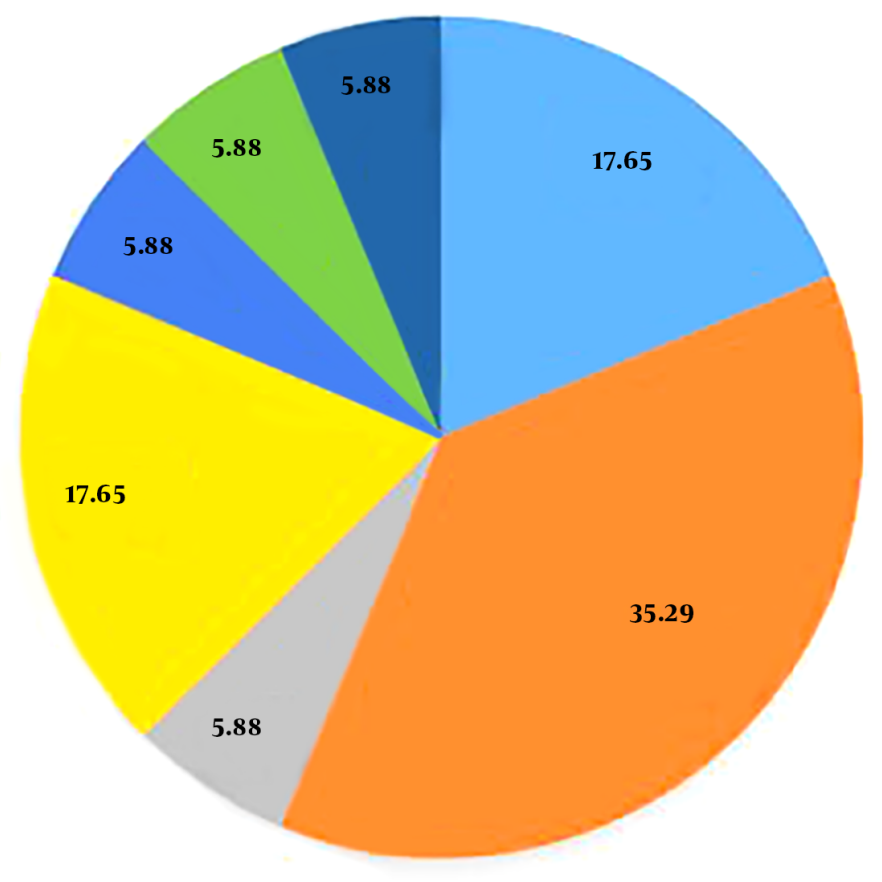

Epidemic Diseases

플 Ebola

[ $\mathrm{H} 7 \mathrm{~N} 9$

Influenza

ㅁ. Tuberclosis

E Cholera

acute Respiratory Infectious

Figure 1. The percentage of epidemic/pandemic outbreaks

sociodemographic information. These mobile-based educations for COVID-19 can be provided through multiple methods such as texts, pictures, voices, videos, and online voice/video communication.

\subsection{Patient Identification and Diagnosis}

Patient identification can be made using various technologies, and one of the fast and low-cost methods of patient identification is mHealth (43). Due to the high ac- 


\begin{tabular}{|c|c|}
\hline $\begin{array}{l}\text { Main Applications of } \\
\text { mHealth }\end{array}$ & Application Types \\
\hline \multirow{8}{*}{ Public health aspects } & Control of the epidemic spread (13) \\
\hline & Notification in outbreaks (12) \\
\hline & $\begin{array}{l}\text { Surveillance: population, healthcare workers, } \\
\text { real-time surveillance }(10-12,22,25)\end{array}$ \\
\hline & $\begin{array}{l}\text { Interventions on nutrition behaviors and } \\
\text { nutrition-related health outcomes (27) for } \\
\text { quarantine and isolation }\end{array}$ \\
\hline & $\begin{array}{l}\text { Contact tracing and monitoring }(14,20,27) \text {, } \\
\text { epidemic tracking }(23)\end{array}$ \\
\hline & Vaccine reminder systems (28) \\
\hline & $\begin{array}{l}\text { Analyzing trends and forecasting (29), disease } \\
\text { mapping systems (13), and health-seeking } \\
\text { behavior (26) }\end{array}$ \\
\hline & $\begin{array}{l}\text { Public awareness (30) and patient } \\
\text { self-monitoring (23) }\end{array}$ \\
\hline \multirow{5}{*}{ Data management } & Data collecting (22) \\
\hline & $\begin{array}{l}\text { Data transmission between healthcare centers } \\
\text { (31) }\end{array}$ \\
\hline & $\begin{array}{l}\text { Reduce health disparities due to facilitating data } \\
\text { exchange (17) }\end{array}$ \\
\hline & Easy access to near real-time information (23) \\
\hline & $\begin{array}{l}\text { Providing timely, high quality, geo-coded, } \\
\text { case-based data (25) }\end{array}$ \\
\hline \multirow{3}{*}{ Educational programs } & Patient and public education (16) \\
\hline & $\begin{array}{l}\text { Health care provider and student education in } \\
\text { epidemic conditions }(15,32)\end{array}$ \\
\hline & $\begin{array}{l}\text { Identifying sociodemographic information for } \\
\text { people education (16) }\end{array}$ \\
\hline \multirow{4}{*}{$\begin{array}{l}\text { Patient identification } \\
\text { and diagnosis }\end{array}$} & Patient identification (25) \\
\hline & Patient and physician relationship (tele-visit) (17) \\
\hline & Mobile laboratories (19) \\
\hline & Disease testing for screening (25) \\
\hline \multirow{3}{*}{ Treatment } & Fever Coach (22) \\
\hline & mHealth Clinic $(24,33)$ \\
\hline & Home visit (tele-visit) (34) \\
\hline
\end{tabular}

cessibility of mobile phones in the society, accounting for more than 7.26 billion users all over the world in 2020 (44), one of the appropriate ways of identifying COVID-19 cases is mHealth. Also, mHealth is a proper method for improving the patient-physician relationship (17), implementing mobile laboratories (19), and testing for screening (25). These applications provide a good opportunity for establishing social distancing as an important way of controlling COVID-19 (45).

\subsection{Treatment}

The treatment of epidemic/pandemic communicable diseases such as COVID-19 imposes a high risk on health care providers (39). Information technology is a good option for decreasing the direct contacts of patients with healthcare providers (46). Based on the results, mHealth can be used for fever Coach (22), home visits (tele-visits) (34), and mHealth clinics $(24,33)$. These are practical to COVID-19 for tackling the disease.

\section{Conclusions}

The main applications of mHealth for epidemic/pandemic outbreaks include public health aspects, data management, educational programs, patient identification and diagnosis, and patient treatment. In the case of COVID, mHealth is one of the best choices to use in the patients' and physicians' relationship as tele-visit, to fever coach, real-time information provision for healthcare providers, and disease detection based on data obtained from different locations. Due to the low cost, ease of use, availability, and accessibility of smart mobiles, the use of mHealth is proposed to tackle COVID-19 at present. However, to eradicate COVID-19, we should use all applications of mHealth as a supportive method alongside other health information technologies. It is suggested that further studies be done to achieve more exact results about the mHealth role in epidemic/pandemic outbreaks and more apps and mobile-based software be developed in similar conditions.

\section{Footnotes}

Authors' Contribution: AG and NA designed the study and the conceptual framework. ML and SM conducted the searches and gathered the data. NA, ML, and SM wrote the first draft of the study and AG revised and finalized the paper. All authors approved the paper.

Conflict of Interests: The authors have no conflict of interest.

Funding/Support: This is an independent study.

\section{References}

1. Silva BM, Rodrigues JJ, de la Torre Díez I, López-Coronado M, Saleem K. Mobile-health: A review of current state in 2015. Journal of Biomedical Informatics. 2015;56:265-72. doi:10.1016/j.jbi.2015.06.003.

2. Steinhubl SR, Muse ED, Topol EJ. Can mobile health technologies transform health care? Jama. 2013;310(22):2395-6. doi: 10.1001/jama.2013.281078. [PubMed: 24158428].

3. Park Y. Emerging New Era of Mobile Health Technologies. Healthcare informatics research. 2016;22(4):253-4. doi: 10.4258/hir.2016.22.4.253. [PubMed: 27895955].

4. Sacks JA, Zehe E, Redick C, Bah A, Cowger K, Camara M, et al. Introduction of Mobile Health Tools to Support Ebola Surveillance and Contact Tracing in Guinea. Global health, science and practice. 2015;3(4):646-59. doi: 10.9745/GHSP-D-15-00207. [PubMed: 26681710].

5. Chan JF, Yuan S, Kok K, To KK, Chu H, Yang J, et al. A familial cluster of pneumonia associated with the 2019 novel coronavirus indicating person-to-person transmission: a study of a family cluster. The Lancet. 2020;395(10223):514-23. 
6. Backer JA, Klinkenberg D, Wallinga J. Incubation period of 2019 novel coronavirus (2019-nCoV) infections among travellers from Wuhan, China, 20-28 January 2020. Euro surveillance : bulletin Europeen sur les maladies transmissibles $=$ European communicable disease bulletin . 2020;25(5):2000062. doi: 10.2807/1560-7917.ES.2020.25.5.2000062. [PubMed: 32046819].

7. Worldometers. COVID-19 Coronavirus Pandemic. 2020, [cited $2020 \mathrm{Apr}$ 01]. Available from: https://www.worldometers.info/coronavirus/.

8. Hodcroft EB. Preliminary case report on the SARS-CoV-2 cluster in the UK, France, and Spain. Swiss Med Wkly. 2020;150(9-10). doi: 10.4414/smw.2020.20212. [PubMed: 32227799].

9. Yajun Y, Wang N, Ou X. Caution should be exercised for the detection of SARS-CoV-2, especially in the elderly. J Med Virol. 2020. doi: 10.1002/jmv.25796. [PubMed: 32227494].

10. Navin K, Krishnan MBM, Lavanya S, Shanthini A. A mobile health based smart hybrid epidemic surveillance system to support epidemic control programme in public health informatics. 2017 International Conference on IoT and Application (ICIOT). 19-20 May 2017. 2017. p.1-4.

11. Lwin MO, Yung CF, Yap P, Jayasundar K, Sheldenkar A, Subasinghe K, et al. FluMob: Enabling Surveillance of Acute Respiratory Infections in Health-care Workers via Mobile Phones. Front Public Health. 2017;5:49. doi: 10.3389/fpubh.2017.00049. [PubMed: 28367433]. [PubMed Central: PMC5355489].

12. Toda M, Njeru I, Zurovac D, O-Tipo S, Kareko D, Mwau M, et al. Effectiveness of a Mobile Short-Message-Service-Based Disease Outbreak Alert System in Kenya. Emerging infectious diseases. 2016;22(4):711-5. doi: 10.3201/eid2204.151459. [PubMed: 26981628].

13. O'Donovan J, Bersin A. Controlling Ebola through mHealth strategies. Lancet Glob Health. 2015;3(1). e22. doi: 10.1016/s2214-109x(14)70357-2. [PubMed: 25539965].

14. Abiola SO, Portman E, Kautz H, Ray Dorsey E. Node view: a mHealth real-time infectious disease interface disease interface - 2014 ebola outbreak case study. Adjunct Proceedings of the 2015 ACM International Joint Conference on Pervasive and Ubiquitous Computing and Proceedings of the 2015 ACM International Symposium on Wearable Computers. Osaka, Japan. Association for Computing Machinery; 2015. 297-300 p.

15. Otu A, Ebenso B, Okuzu O, Osifo-Dawodu E. Using a mHealth tutorial application to change knowledge and attitude of frontline health workers to Ebola virus disease in Nigeria: a before-and-after study. $\mathrm{Hu}$ man Resources for Health. 2016;14(1):5. doi:10.1186/s12960-016-0100-4.

16. Gu H, Jiang Z, Chen B, Zhang JM, Wang Z, Wang X, et al. Knowledge, Attitudes, and Practices Regarding Avian Influenza A (H7N9) Among Mobile Phone Users: A Survey in Zhejiang Province, China. JMIR Mhealth Uhealth. 2015;3(1). e15. doi: 10.2196/mhealth.3394. [PubMed: 25653213]. [PubMed Central: PMC4342637].

17. Phillips AL, Kumar D, Patel S, Arya M. Using text messages to improve patient-doctor communication among racial and ethnic minority adults: an innovative solution to increase influenza vaccinations. Preventive medicine. 2014;69:117-9. doi: 10.1016/j.ypmed.2014.09.009. [PubMed: 25241643].

18. Gashu KD, Gelaye KA, Mekonnen ZA, Lester R, Tilahun B. Does phone messaging improves tuberculosis treatment success? A systematic review and meta-analysis. BMC Infectious Diseases. 2020;20(1):42. doi: 10.1186/s12879-020-4765-X.

19. Racine T, Kobinger GP. Challenges and perspectives on the use of mobile laboratories during outbreaks and their use for vaccine evaluation. Human vaccines \& immunotherapeutics. 2019;15(10):2264-8. doi: 10.1080/21645515.2019.1597595. [PubMed: 30893007].

20. Danquah LO, Hasham N, MacFarlane M, Conteh FE, Momoh F, Tedesco $\mathrm{AA}$, et al. Use of a mobile application for Ebola contact tracing and monitoring in northern Sierra Leone: a proof-of-concept study. BMC Infectious Diseases. 2019;19(1):810. doi: 10.1186/s12879-019-4354-z.

21. Rebaudet S, Bulit G, Gaudart J, Michel E, Gazin P, Evers C, et al. The case-area targeted rapid response strategy to control cholera in Haiti: a four-year implementation study. PLoS Negl Trop Dis. 2019;13(4). e0007263. doi: 10.1371/journal.pntd.0007263. [PubMed: 30990822].
[PubMed Central: PMC6485755].

22. Kim M, Yune S, Chang S, Jung Y, Sa SO, Han HW. The Fever Coach Mobile App for Participatory Influenza Surveillance in Children: Usability Study. JMIR Mhealth Uhealth. 2019;7(10). e14276. doi: 10.2196/14276. [PubMed: 31625946]. [PubMed Central: PMC6823603].

23. Fujibayashi K, Takahashi H, Tanei M, Uehara Y, Yokokawa H, Naito T. A New Influenza-Tracking Smartphone App (Flu-Report) Based on a Self-Administered Questionnaire: Cross-Sectional Study. JMIR Mhealth Uhealth. 2018;6(6). e136. doi: 10.2196/mhealth.9834. [PubMed: 29875082]. [PubMed Central: PMC6010834].

24. Guetiya Wadoum RE, Samin A, Mafopa NG, Giovanetti M, Russo G, Turay $P$, et al. Mobile health clinic for the medical management of clinical sequelae experienced by survivors of the 2013-2016 Ebola virus disease outbreak in Sierra Leone, West Africa. Eur J Clin Microbiol Infect Dis. 2017;36(11):2193-200. doi:10.1007/s10096-017-3045-1. [PubMed: 28695354].

25. Rosewell A, Makita L, Muscatello D, John LN, Bieb S, Hutton R, et al. Health information system strengthening and malaria elimination in Papua New Guinea. Malar J. 2017;16(1):278. doi: 10.1186/s12936-0171910-0. [PubMed: 28679421]. [PubMed Central: PMC5499047].

26. Kuehne A, Lynch E, Marshall E, Tiffany A, Alley I, Bawo L, et al. Mortality, Morbidity and Health-Seeking Behaviour during the Ebola Epidemic 2014-2015 in Monrovia Results from a Mobile Phone Survey. PLoS Negl Trop Dis. 2016;10(8). e0004899. doi: 10.1371/journal.pntd.0004899. [PubMed: 27551750]. [PubMed Central: PMC4994996].

27. Villinger K, Wahl DR, Boeing H, Schupp HT, Renner B. The effectiveness of app-based mobile interventions on nutrition behaviours and nutrition-related health outcomes: A systematic review and meta-analysis. Obes Rev. 2019;20(10):1465-84. doi: 10.1111/obr.12903. [PubMed: 31353783]. [PubMed Central: PMC6852183].

28. Lehnert JD, Shevach A, Walker S, Wang R, Fitzgerald TJ, Graitcer SB. Development and pilot testing of a text message vaccine reminder system for use during an influenza pandemic. Hum Vaccin Immunother. 2018;14(7):1647-53. doi: 10.1080/21645515.2018.1440162. [PubMed: 29451833]. [PubMed Central: PMC6067886].

29. Girond F, Randrianasolo L, Randriamampionona L, Rakotomanana F, Randrianarivelojosia M, Ratsitorahina M, et al. Analysing trends and forecasting malaria epidemics in Madagascar using a sentinel surveillance network: a web-based application. Malar J. 2017;16(1):72. doi: 10.1186/s12936-017-1728-9. [PubMed: 28193215]. [PubMed Central: PMC5307694].

30. Alqahtani AS, Rashid H, Basyouni MH, Alhawassi TM, BinDhim NF. Public response to MERS-CoV in the Middle East: iPhone survey in six countries. J Infect Public Health. 2017;10(5):534-40. doi: 10.1016/j.jiph.2016.11.015. [PubMed: 28185821]. [PubMed Central: PMC7102840].

31. Randriamiarana R, Raminosoa G, Vonjitsara N, Randrianasolo R, Rasamoelina $\mathrm{H}$, Razafimandimby $\mathrm{H}$, et al. Evaluation of the reinforced integrated disease surveillance and response strategy using short message service data transmission in two southern regions of Madagascar, 2014-15. BMC Health Serv Res. 2018;18(1):265. doi: 10.1186/s12913018-3081-2. [PubMed: 29631631]. [PubMed Central: PMC5891931].

32. Walsh S, De Villiers MR, Golakai VK. Introducing an E-learning Solution for Medical Education in Liberia. Ann Glob Health. 2018;84(1):1907. doi: 10.29024/aogh.21. [PubMed: 30873817]. [PubMed Central: PMC6748226].

33. Manusov EG, Diego VP, Smith J, Garza J2, Lowdermilk J, Blangero J, et al. UniMovil: A Mobile Health Clinic Providing Primary Care to the Colonias of the Rio Grande Valley, South Texas. Front Public Health. 2019;7:215. doi: 10.3389/fpubh.2019.00215. [PubMed: 31497586]. [PubMed Central: PMC6712363].

34. Rotheram-Borus MJ, Le Roux K, Le Roux IM, Christodoulou J, Laurenzi $\mathrm{C}$, Mbewu N, et al. To evaluate if increased supervision and support of South African Government health workers' home visits improves maternal and child outcomes: study protocol for a randomized con- 
trol trial.Trials. 2017;18(1):368. doi: 10.1186/s13063-017-2074-5. [PubMed: 28784142]. [PubMed Central: PMC5547508].

35. Stein-Zamir C, Abramson N, Edelstein N, Shoob H, Zentner G, Zimmerman DR. Community-Oriented Epidemic Preparedness and Response to the Jerusalem 2018-2019 Measles Epidemic. Am J Public Health. 2019;109(12):1714-6. doi: 10.2105/ajph.2019.305343. [PubMed: 31622151]. [PubMed Central: PMC6836774].

36. Stoecklin SB, Rolland P, Silue Y, Mailles A, Campese C, Simondon A, et al. First cases of coronavirus disease 2019 (COVID-19) in France: surveillance, investigations and control measures, January 2020. Eurosurveillance. 2020;25(6).

37. Liu S, Poccia S, Candan KS, Chowell G, Sapino ML. epiDMS: Data Management and Analytics for Decision-Making From Epidemic Spread Simulation Ensembles.J Infect Dis. 2016;214(suppl_4):S427-s432. doi: 10.1093/infdis/jiw305. [PubMed: 28830107].

38. Mohanty B, Chughtai A, Rabhi F. Use of Mobile Apps for epidemic surveillance and response-availability and gaps. Global Biosecurity. 2019;1(2).

39. Aslani N, Garavand A. The role of telemedicine to control CoVID-19. Arch Clin Infect Dis. 2020;15(COVID-19). e102949.

40. Lee BY. The role of internists during epidemics, outbreaks, and bioterrorist attacks. Journal of general internal medicine. 2007;22(1):1316. doi: 10.1007/s11606-006-0030-2. [PubMed: 17351853].

41. Madhav N, Oppenheim B, Gallivan M, Mulembakani P, Rubin E, Wolfe
N. Pandemics: risks, impacts, and mitigation. Disease Control Priorities: Improving Health and Reducing Poverty. 3rd ed. The International Bank for Reconstruction and Development/The World Bank; 2017.

42. Tavakoli A, Ilkhani M, Ashktorab T, Rohani C. The Educational Needs of Iranian Family Caregivers of Patients with Advanced Heart Failure: A Qualitative Study. International Cardiovascular Research Journal. 2018;12(4).

43. Pastorino B, Muyembe-Tamfum JJ, Bessaud M, Tock F, Tolou H, Durand JP, et al. Epidemic resurgence of Chikungunya virus in democratic Republic of the Congo: identification of a new central African strain.JMed Virol.2004;74(2):277-82. doi: 10.1002/jmv.20168. [PubMed: 15332277].

44. O'Dea S. Statista. Forecast number of mobile users worldwide 2019-2023. 2020, [cited 2020 Mar 31]. Available from: https://www.statista.com/ statistics/218984/number-of-global-mobile-users-since-2010/.

45. Anderson RM, Heesterbeek H, Klinkenberg D, Hollingsworth TD. How will country-based mitigation measures influence the course of the COVID-19 epidemic? The Lancet. 2020;395(10228):931-4.

46. Siwicki B. Telemedicine during COVID-19: Benefits, limitations, burdens, adaptation. Healthcare ITS News; 2020, [cited 2020 Mar 22]. Available from: https://www.healthcareitnews.com/news/ telemedicineduring-covid-19-benefits-limitations-burdensadaptation. 